\title{
Efficacy and safety of transarterial chemoembolization combined to conformal radiotherapy for uninodular hepatocellular carcinoma
}

\author{
Philippe Merle ${ }^{1}$, Agnes Rode ${ }^{2}$, Redouane Benlaredj ${ }^{1}$, Marie Cuinet ${ }^{2}$, Tammam Said ${ }^{1}$, Fulgence Bathaix ${ }^{1}$, \\ Ciprian Enachescu ${ }^{3}$, Francoise Mornex ${ }^{3}$ \\ ${ }^{1}$ Hepatology Unit, Groupement Hospitalier Lyon Nord, Lyon, France \\ ${ }^{2}$ Department of Radiology, Groupement Hospitalier Lyon Nord, Lyon, France \\ ${ }^{3}$ Department of Radiotherapy, Centre Hospitalier Lyon Sud, Lyon, France
}

Received August 14, 2014; Revised September 28, 2014; Accepted September 29, 2014; Published Online October 02,2014

\section{Original Article}

\begin{abstract}
Purpose: A proportion of patients with uninodular hepatocellular carcinoma (HCC) cannot benefit from potential curative therapies such as liver transplantation, surgical resection or radiofrequency ablation. Thus, they are prone to receive transarterial chemoembolization (TACE) that is a palliative option with low probability of both complete response and prolonged local control. Herein, we assessed the combination of TACE and 3D-high dose conformal radiotherapy (3D-HDCRT) for efficacy and safety in HCC. Methods: We retrospectively analyzed the outcome of 35 consecutive patients with uninodular HCC $\leq 100$ mm, treated by one course of TACE combined to 3D-HDCRT. The follow-up consisted on clinics, biology, hepatic CT-scan or MRI at month-1 and -3, and thereafter every 3 months. Results: Complete response was obtained in $80 \%$ of patients following mRECIST criteria ( $95 \%$ in HCC $\leq 50 \mathrm{~mm}$, and $60 \%$ in HCC $>50 \mathrm{~mm}$ ) with uncommon local recurrence (11\%), overall survival rates of $79 \%, 59 \%$ and $44 \%$ at respectively 1, 2 and 3 years (median, 37.3 months), and $11.4 \%$ grade- $3 / 4$ toxicities. Pre-therapeutic $\alpha$-fetoprotein level $\geq 200 \mathrm{ng} / \mathrm{mL}$ was found as a strong predictor of poorer outcome. Conclusion: We showed that TACE combined to 3D-HDCRT can be highly efficient to reach local control and interesting overall survival rates for uninodular HCC, with limited severe toxicities for Child-Pugh A patients. Subsequent prospective controlled trials are warranted for comparison with therapeutic standards.
\end{abstract}

Keywords: Hepatocellular carcinoma; Conformal Radiotherapy; Chemoembolization

\section{Introduction}

Hepatocellular carcinoma (HCC), one of the most common cancer worldwide, is the main cause of mortality among cirrhotic patients, and ranks third in terms of death by cancer. HCC prognosis greatly varies according to tumour size and spread as well as liver functions and general status. , $^{1,2}$ Except a restrictive population of very early or early stage HCCs that are eligible for curative options such as orthotopic liver transplantation (OLT) or radiofrequency ablation (RFA), the best prognosis remains with surgical resection. ${ }^{3}$ This latter can be considered as a curative option, especially for patients with uninodular HCC, and its feasibility is closely linked to the tumour bulk, absence of clinically relevant portal hypertension, and conserved liver functions. Tumour size is not a limiting issue per se, but the best outcome post-surgery remains for patients with $\mathrm{HCC} \leq 5 \mathrm{~cm}$. However a pattern of concerns arises from uninodular HCCs since they might not be eligible for curative options, and thus are candidate for trans arterial intrahepatic chemoembolization (TACE).

TACE is a palliative option with the best reported median overall survival around 20 months (mo). TACE induces extensive tumor necrosis in more than $50 \%$ of HCCs, but most of tumors do not achieve a complete response (around 20\% complete responses following liver-adapted RECIST criteria), and TACE is of limited efficacy in terms of progression-free survival. Indeed, within or around the capsule which is supplied by both arterial and portal blood, tumour cells remain viable and are frequently responsible for subsequent progression, this consideration prompting treatment repetitions. As the tumour response variable appears as an independent predictive factor of survival, it seems of likelihood that com- 
plementary approaches tending to increase complete necrosis could be of benefit on survival. ${ }^{4-10}$

Combination of three-dimensional high-dose conformal radiotherapy (3D-HDCRT) and TACE may remedy the limitation of TACE alone by adding anti-cancerous synergy, and serving the purpose of residual cancer cell eradication after TACE. All the so far published studies on TACE + 3D-HDCRT combination are uncontrolled trials or retrospective analysis. Initial studies tested norm fractionated schedules of 3D-HDCRT following TACE (25-69.3 Gy, 1.6-2 Gy/daily fraction), leading to interesting response rates (49 to 63\%), and around 18 months overall survival. Of interest, toxicities were reduced, including only transient elevation of liver function tests in all patients, but without treatment-related death. ${ }^{11,12}$ Subsequent studies compared TACE + 3D-HDCRT combination to TACE alone in retrospective analysis, and clearly isolated irradiation as an independent predictor of tumour response and prolonged survival. ${ }^{13-15}$ In the present study, we showed that, for uninodular HCC developed in noncirrhotics or Child-Pugh A cirrhotics, the combination of TACE and 3D-HDCRT led to high complete response rates, low risk of local recurrence and acceptable toxicity.

\section{Methods and Materials}

\section{Study Characteristics}

In our centre, every HCC patient is mandatory reviewed by a weekly multidisciplinary board composed of liver surgeons and transplanters, interventional radiologists, medical oncologists, radiotherapists and hepatologists. Therapeutic strategies are defined following international guidelines. ${ }^{7} \mathrm{We}$ retrospectively analyzed the outcome of 35 consecutive patients treated in our centre by TACE + 3D-HDCRT combination. All the patients fullfiled the following criteria: histologic or cytologic proven and/or noninvasive imaging-based diagnosed HCC using AASLD criteria with CT-scan and/or magnetic resonance imaging (MRI) ${ }^{7}$; solitary HCC nodule $\leq 100$ mm developed within a nontransplanted liver; patient $\geq 18$ years not suitable for standard curative options (OLT, surgical resection or RFA) following international guidelines 7 ; Child-Pugh A5 to B7 status if cirrhosis; absence of truncular or lobar portal vein invasion, or suprahepatic vein invasion; absence of previous liver irradiation; performance status $<2$; all the patients received informations on the treatment schedule based on previously published data and freely consented for this therapeutic association.

\section{TACE Procedure}

One single course of TACE was performed. All the patients underwent baseline angiography of the celiac trunk, superior mesenteric artery and hepatic artery using a peripheral arterial approach. TACE was performed with suspension of Doxorubicin (50 mg) and $10 \mathrm{ml}$ of lipiodol, before emboliza- tion with mixed absorbable gelatin sponge (Curaspon ${ }^{\circledR}$ ). After selecting the tumor-bearing arteries, and when possible for the most hyperselective treatment, a microcatheter was used for the drug infusion in the segmental or supra segmental arteries. Patients were discharged after recovery followed by physical examination and blood test 3 days after TACE. We contraindicated patients to arterial procedure when presence of impaired clotting tests (platelet count below $50 \times 10^{9} / \mathrm{L}$ or prothrombin activity below $50 \%$ ), renal failure, severe atheromatosis; any contraindication to doxorubicin (serum bilirubin $>50 \mu \mathrm{mol} / \mathrm{L}$, leucocyte count $<3 \times$ $10 \% / \mathrm{L}$, cardiac ejection fraction $<50 \%$ ); or endstage tumoral disease -BCLC-D).

\section{Radiation Therapy}

3D-HDCRT radiation therapy started 10 days post-TACE ${ }^{16}$, including active breathing control ("respiratory gating"). ${ }^{17}$ The treatment planning computed tomography (CT) scans were performed in the position of 3D-HDCRT. The lipiodol tumor uptake was an effective target to define the contours of the lesions. Nontumor and tumor volumes were outlined by an experienced radiation oncologist from data of inspiratory hold sequences as previously described. ${ }^{18}$ As the gating technique was used, radiation was delivered during the inspiration phase. As previously reported, radiation doses were determined by the dose-volume histograms (DVH) 19,20 and normal tissue complication probabilities (NTCP). ${ }^{21}$ Total dose was 54 Gy. However lower doses could be used - i.e. 45 or 30 Gy - depending on whether the volume of normal liver parenchyma receiving $50 \%$ of the isocenter dose was respectively comprised between $33 \%$ and $66 \%$, or > 66\%. Dose constraints were included on the stomach and duodenum. Fractionation was $3 \mathrm{~Gy} /$ fraction, 5 fractions/week, with photon beam energy $>10 \mathrm{MeV}$. Clinical, biologic and radiologic follow-up were performed 1 month after the end of radiotherapy, and subsequently every 3 months. The same dosimetric schedule was equally applied for both cirrhotic and noncirrhotic patients, taking account that all cirrhotic patients had rather well conserved liver functions (Child-Pugh A5 to B7). We did not use non coplanar fields routinely. Either 2 opposed fields were used, or a technique of 5 to 8 fields was used, according to the tumor location and tumor size. The proximity of stomach and duodenum was an important decision tool in the choice of the fields arrangement.

\section{Assessment of Efficacy and Toxicity}

Efficacy of the TACE + 3D-HDCRT combination therapy was assessed on: tumor response by injected dynamic CT-scan (or MRI) following liver adapted-RECIST criteria; overall survival (OS); progression-free survival (PFS); time to relapse (TTR) for complete responders (CR), or time to progression (TTP) for partial responders (PR) or stable diseases (SD); safety using both the Child-Pugh score for liver toxicity, the national cancer institute common toxicity criteria (NCI-CTC) 
version 3.0 for early toxicity (from month -1 to months -3 ), and the late effects on normal tissues-subjective, objective, management and analytic (LENTSOMA) scale for late toxicity (from months-6 to months-12). ${ }^{22}$

\section{Statistical Methods}

Probabilities of survival were calculated from the day of screening CT-scan (MRI) imaging according to Kaplan and Meier. Relationship between each of the variables and survival was assessed by log-rank test in univariate analysis. Relationships between the different variables were analyzed by the CHI-2 test ( $\mathrm{P}$ value $<.05$ indicating significance). Multivariate analyses were performed using Cox models for overall survival, PFS and TTR/TTP. All statistical tests were two-sided and p-values $<.05$ were considered significant. Statistical analysis was performed using MedCalc version 12.3.0.0 software package.

\section{Results}

Between April 2005 and November 2010, 35 patients with uninodular HCC were treated with TACE + 3D-HDCRT combination therapy, and the medical records of these patients were retrospectively reviewed. All the patients received both TACE and 3D-HDCRT, without any drop-out between TACE and 3D-HDCRT due to TACE toxicity. Variables from HCC patients are summarized in Table 1. Briefly, the mean age of patients was $>70$ years, consisting mainly of Child-Pugh A cirrhotic caucasian males. All patients had uninodular HCC, either $\leq 50 \mathrm{~mm}$ for 20/35 (57\%), or $>50 \mathrm{~mm}$ for 15/35 (43\%). Follow-up period was $23.8 \pm 11.7$ months $($ mean $\pm \mathrm{SD})$. The local control rate reached 100\%: 28/35 (80\%) CR, 6/35 (17\%) PR, and 1/35 (3\%) SD (Figure 1).

TABLE 1: Patient characteristics at baseline.

\begin{tabular}{|c|c|}
\hline Number of patients & 35 \\
\hline \multicolumn{2}{|l|}{ Demographic } \\
\hline Age (years) & $54-85($ mean $72.8 \pm 8.2 ;$ median 74$)$ \\
\hline Gender (male/female) & $28 / 7$ \\
\hline Ethnicity & 34 caucasians, 1 african \\
\hline Underlying liver disease & 29 cirrhosis / 6 noncirrhotic livers \\
\hline Etiology & $\begin{array}{l}\text { alcohol (13), alcohol + NASH or dysmetabolic } \\
\text { syndrome (2), NASH or dysmetabolic syn- } \\
\text { drome (3), HCV (8), HCV + NASH or } \\
\text { dysmetabolic syndrome (2), HBV (3), hemo- } \\
\text { chromatisis (1), cryptogenic (3) }\end{array}$ \\
\hline \multicolumn{2}{|l|}{ Tumor description } \\
\hline \multicolumn{2}{|l|}{ Radiological characteristics } \\
\hline Size of the single nodule $(\mathrm{mm})$ & Range 23-88 (mean $48.9 \pm 17.1$; median 50$)$ \\
\hline Adjacent neoplastic segmental portal vein thrombosis & 2 \\
\hline Extrahepatic spread & 0 \\
\hline Alpha-fetoprotein (ng/mL) & $1-11170($ mean $480.1 \pm 1910.8 ;$ median 8$)$ \\
\hline \multicolumn{2}{|l|}{ Staging system } \\
\hline BCLC staging classification & A (28), C (7) \\
\hline \multicolumn{2}{|l|}{ Liver function } \\
\hline Bilirubin & $4-32 \mu \mathrm{M} / \mathrm{L}($ mean $15 \pm 7.3$; median 11$)$ \\
\hline $\operatorname{ASAT}(\mathrm{N}<35 \mathrm{IU} / \mathrm{L})$ & 15-187 IU/L (mean $42 \pm 32.9 ;$ median 27$)$ \\
\hline $\operatorname{ALAT}(\mathrm{N}<45 \mathrm{IU} / \mathrm{L})$ & 10-138 IU/L (mean $35 \pm 27$; median 29) \\
\hline Albumin & 23.1-47.6 g/L (mean $37 \pm 5.4 ;$ median 39) \\
\hline Alkaline phosphatases $(\mathrm{N}<130 \mathrm{IU} / \mathrm{L})$ & 69-259 IU/L (mean $123 \pm 48.2 ;$ median 111$)$ \\
\hline Gamma-glutamyl transpeptidase $(\mathrm{N}<55 \mathrm{IU} / \mathrm{L})$ & 39-683 IU/L (mean $163 \pm 152.2 ;$ median 99) \\
\hline Serum creatinine $(\mathrm{N}<100 \mathrm{IU} / \mathrm{L})$ & 69-164 $\mu \mathrm{M} / \mathrm{L}($ mean $94 \pm 26.3 ;$ median 91) \\
\hline Serum sodium $(\mathrm{N}=135-145 \mathrm{mEq} / \mathrm{L})$ & $134-146 \mathrm{mEq} / \mathrm{L}($ mean $139 \pm 2.7 ;$ median 138$)$ \\
\hline Prothrombine time $(\mathrm{N} \geq 70 \%)$ & $72-110 \%($ mean $85 \pm 12.2 ;$ median 81$)$ \\
\hline Platelet count $(\mathrm{N}=150-450 \mathrm{Giga} / \mathrm{L})$ & 56-377 Giga/L (mean $159 \pm 92.3 ;$ median 143$)$ \\
\hline \multicolumn{2}{|l|}{ Child-Pugh class } \\
\hline $\mathrm{A} 5$ / A6 / B7 & $23 / 9 / 3$ \\
\hline \multicolumn{2}{|l|}{ General health } \\
\hline Performance status (ECOG) $0 / 1$ & $30 / 5$ \\
\hline Pain & 0 \\
\hline Constitutional syndrome & 0 \\
\hline
\end{tabular}





FIG. 1: CT-scan image series of HCC tumor with arterial enhancement before therapy (A), Lipiodol staining but remaining arterial enhancement 5 days after TACE (B), and complete devascularization 3 months after 3D-HDCRT (C).

\section{Before therapy}

5 days post TACE Before 3D-HDCRT

\section{3 months post} 3D-HDCRT
Among the $28 \mathrm{CR}$ pts, arterial contrast enhancement disappeared at month-1 for 17 pts (61\%), at month-3 for 9 pts (32\%), and month-6 for 2 pts (7\%) post-3D-HDCRT. Adjacent neoplastic segmental portal vein invasion (2 patients) did not impact on the parenchymal tumor response probability, and the portal vein invasion showed arterial uptake disappearance and was devoid of progression within the portal tree all along the follow-up. CR probability was higher for HCCs $\leq$ $50 \mathrm{~mm}(19 / 20,95 \%)$ vs. HCCs $>50 \mathrm{~mm}(9 / 15,60 \%)$ (CHI-2, $P<.02$ ). Pre-therapeutic $\alpha$-fetoprotein levels (AFP) did not impact on CR probability: $88 \%$ for AFP $\geq 200 \mathrm{ng} / \mathrm{mL}$ vs. $78 \%$ for AFP $<200 \mathrm{ng} / \mathrm{mL} ; \mathrm{P}=\mathrm{NS}$ ). In contrast, the absence of normalization of AFP in CR pts with high pre-therapeutic AFP level, was highly predictive of metastasis occurrence (Table 2).

Median overall survival (OS) reached 37.3 months (range 5-50): $79 \%, 59 \%$ and $44 \%$ at respectively 1, 2 and 3 years
(Figure 2A). In multivariate analysis, pre-therapeutic AFP $\geq$ $200 \mathrm{ng} / \mathrm{mL}$ was the best and unique significant predictive factor of shorter overall survival (17 vs. 39 months; $\mathrm{P}=.01$ ) (Table 3), whereas tumor size $>50 \mathrm{~mm}$ and absence of CR status were not. By the way, CR status tended to be associated with longer OS, being aware that most non-CR were PR. Thus they could subsequently benefit from RFA or TACE on the tumorous residues, finally leading to $C R$ of the target lesion. Causes of death $(n=19)$ were terminal progression of HCC ( $\mathrm{n}=8)$ (mean $\pm \mathrm{SD}=26 \pm 12.1$ months), Mendelson's syndrome, characterized by a bronchopulmonary reaction following aspiration of gastric contents during general anaesthesia, occurring a few hours post-surgical resection of HCC recurrence $(\mathrm{n}=1)$ at month-41, digestive bleeding $(\mathrm{n}=$ $1)$ at month-5, perforative umbilical hernia $(n=1)$ at month-34, bacterial pneumonia $(\mathrm{n}=1)$ at month-50, acute alcoholic hepatitis $(\mathrm{n}=1)$ at month-8, pancreatic adenocarcinoma $(\mathrm{n}=1)$ at month-10, hepatorenal syndrome $(\mathrm{n}=2)$ at 
month-17 and month-19, spontaneous bacterial peritonitis (n = 1 ) at month-25, liver failure $(\mathrm{n}=1)$ at month-11, and unknown cause $(\mathrm{n}=1)$ at month-11. Progression-free survival (PFS) was 19 months in the whole population (Figure 2B). In multivariate analysis, pre-therapeutic AFP $\geq 200 \mathrm{ng} / \mathrm{mL}$ and albuminemia $<35 \mathrm{~g} / \mathrm{L}$ were significant and independent predictive factors of shorter PFS (Table 4), respectively 11 vs. 24 months $(\mathrm{P}=.02)$, and 7.5 vs. 24 months $(\mathrm{P}=.02)$.

TABLE 2: List of the 28 CR patients after TACE+3D-HDCRT. In bold and italic are listed patients with high pre-therapeutic AFP without normalization post-therapy.

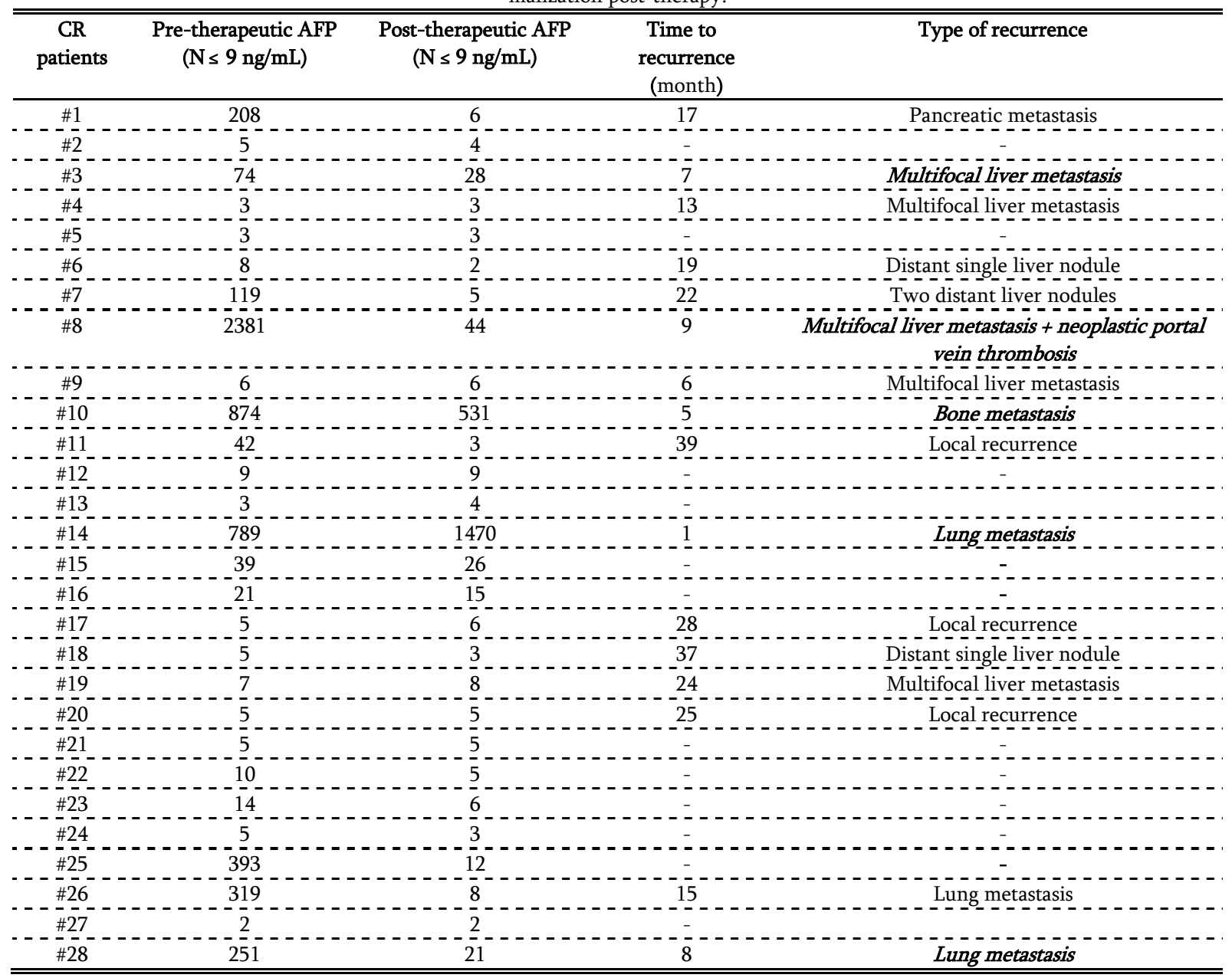





FIG. 2: Kaplan-Meier curves for (A) overall survival probability (OS), (B) progression-free survival probabitity (PFS), and (C) recurrence/progression-free time probability (TTR/TTP). 
TABLE 3: Factors influencing overall survival.

\begin{tabular}{|c|c|c|c|c|}
\hline $\begin{array}{l}\text { Cox Proportional-Hazards Re- } \\
\text { gression for Univariate and Mul- } \\
\text { tivariate Analysis }\end{array}$ & $\begin{array}{l}\text { Univariate analy- } \\
\text { sis } \mathrm{HR}(95 \% \mathrm{CI})\end{array}$ & $\mathrm{P}$-value & $\begin{array}{l}\text { Multivariate analy- } \\
\text { sis HR ( } 95 \% \mathrm{CI})\end{array}$ & $\begin{array}{l}\text { Wald } \\
\text { test, } \\
\text { P-value } \\
\end{array}$ \\
\hline Age older than 70 years $(\mathrm{n}=24)$ & 352 & .82 & & \\
\hline Male gender & $\begin{array}{l}(0.31-2.53) \\
-0.75 \\
(0.26-2.16)\end{array}$ & .60 & & \\
\hline Cirrhosi & $\begin{array}{l}3.72 \\
(0.49-28.3)\end{array}$ & .20 & & \\
\hline HBV etio & $(0.00-69.7 \mathrm{E}+153)$ & $\overline{.94}$ & & \\
\hline HCV eti & $\begin{array}{l}1.04 \\
(0.36-2.96)\end{array}$ &.$\overline{.9}$ & & \\
\hline Alcohol & $(0.48-3.17)$ & .65 & & \\
\hline Other et & $(0.64-5.31)$ & .25 & & \\
\hline Platelet coun & $(0.91-7.20)$ & .07 & & \\
\hline Albumi & $\begin{array}{l}2.54 \\
(0.97-6.66)\end{array}$ & .05 & & \\
\hline Bilirubinemia $>20 \mu \mathrm{M} / \mathrm{L}(\mathrm{n}=8)$ & $(0.99-6.75)$ & .05 & & \\
\hline $\mathrm{AFP} \geq 200 \mathrm{ng} / \mathrm{mL}(\mathrm{n}=8)$ & $\begin{array}{l}3.88 \\
(1.23-12.2)\end{array}$ & & $\begin{array}{c}3.88 \\
(1.23-12.2)\end{array}$ & \\
\hline BCLC stage non-A $(\mathrm{n}=7)$ & $(0.27-2.77)$ & .82 & & \\
\hline Tumor size $>50 \mathrm{~mm}$ & $(0.60-3.90)$ & 36 & & \\
\hline $\begin{array}{l}\text { Absence of complete response } \\
\text { after TACE + 3D-HDCRT }(\mathrm{n}=7)\end{array}$ & $\begin{array}{l}2.28 \\
(0.72-7.22)\end{array}$ & .16 & & \\
\hline
\end{tabular}

Among CR pts $(\mathrm{n}=28)$, recurrences occurred in 16/28 (57\%) pts with a mean time of $20.7 \pm 10.2$ months (Figure $2 \mathrm{C}$ ). Only three of them $(11 \%)$ were local recurrence inside radiation fields. Other recurrences were either intra-hepatic outside radiation fields ( $\mathrm{n}=8)(17 \pm 10.7$ months $)$ or as distant visceral metastasis $(\mathrm{n}=5)(7.7 \pm 8.3$ months $)$. Subsequent treatments were TACE for multifocal intra-hepatic recurrence $(n=4)$, RFA for unifocal hepatic recurrence $(n=4)$ or surgical resection $(\mathrm{n}=1)$, sorafenib for neoplastic portal vein invasion or distant metastasis $(n=3)$, best supportive care for metastatic recurrence and alteration of general status (BCLC stage D) (n $=2$ ). Among non-CR $(n=7)$, three of them could subsequently benefit from TACE $(n=2)$ or RFA $(n=1)$. Progression occurred in three non-CR, such as intra-hepatic progression $(\mathrm{n}=2)(20.5 \pm 7.8$ months $)$ and distant visceral metastasis at month-3 $(\mathrm{n}=1)$. In multivariate analysis, pre-therapeutic AFP $\geq 200 \mathrm{ng} / \mathrm{mL}$ was highly predictive of shorter TTR (Table 5): 8.7 vs. 25.1 months; $\mathrm{P}=.003$ ). Pre-therapeutic AFP $\geq 200 \mathrm{ng} / \mathrm{mL}$ was predictive of HCC aggressiveness since present in $80 \%$ of patients who developed later occurrence of distant visceral metastasis or portal vein invasion, vs. $17 \%$ of patients with later intra-hepatic recurrence outside radiation fields, vs. $0 \%$ of patients with later recurrence inside radiation fields. Median TTR tended to associate with tumor size: 24.4 months for HCCs $\leq 50 \mathrm{~mm} v s$. 15.9 months for HCCs $>50 \mathrm{~mm}(\mathrm{P}=.0597)$.

Liver toxicity was assessed by the Child-Pugh score. The pre-therapetic values $(5.5 \pm 0.8 ; \mathrm{n}=35 \mathrm{pts})$ significantly worsened from month-1 $(6.0 \pm 1.0$; $\mathrm{t}$-student, $\mathrm{P}=.0184 ; \mathrm{n}=35$ pts evaluable) to month-3 $(6.4 \pm 1.5 ; \mathrm{P}=.0038 ; \mathrm{n}=35$ pts evaluable) reaching the nadir at month $-6(6.7 \pm 1.6$; $\mathrm{P}=.0065$; $\mathrm{n}=33 \mathrm{pts}$ evaluable due to one loss of view, and one death by digestive bleeding). Thereafter, a slight although nonsignificant improvement occurred at month-9 $(6.6 \pm 1.6 ; \mathrm{P}=\mathrm{NS} ; \mathrm{n}=$ 30 pts evaluable due to one death by acute alcoholic hepatitis, and two death by multifocal progression of HCC) and month-12 $(6.4 \pm 1.5 ; \mathrm{P}=\mathrm{NS} ; \mathrm{n}=27$ pts evaluable due to one death by pancreatic adenocarcinoma, one death by liver failure, and one death of unknown cause). 
TABLE 4: Factors influencing PFS.



No early grade- $3 / 4$ toxicities (month-1 and month-3) were reported (Table 5). Regarding late grade-3/4 toxicities (months 6, 9, 12), 2 pts (5.7\%) developed grade-3 ascitis at month- 6 , one of them cumulating grade- 4 variceal bleeding. Two additional pts developed grade- 3 ascitis or gastric bleeding at month-12, leading to a cumulative rate of $11.4 \%$ grade- $3 / 4$ toxicities. Noticeably, only the pt developing both grade- 3 ascitis and grade- 4 variceal bleeding got lethal behaviour that could be directly and obviously related to the TACE + 3D-HDCRT combination therapy. Ascitis (all grades included) was the most common side effect since occurring in 7/35 patients (20\%) (Table 6).

\section{Discussion}

In the present study, we aimed to catch the antitumor effect and safety of TACE + 3D-HDCRT combination therapy. We focused on a specific subset of patients - i.e. those with uninodular HCC tumor $\leq 100 \mathrm{~mm}$, ineligible for curative ther apies (OLT, surgical resection or RFA), and developed in chronic liver disease (mainly cirrhosis) devoid of significant hepatic insufficiency. We demonstrated that TACE + 3D-HDCRT can reach high rate of tumor response, interesting survival rates and fairly good tolerance. Therapeutic strategies are defined following international guidelines. ${ }^{7}$ Patients non eligible for surgery are patients with: i) non-stage A HCC in the BCLC classification; ii) significative portal hypertension with esophageal varices and/or porto-sushepatic gradient $>10 \mathrm{~mm} \mathrm{Hg}$; iii) comorbidities forbidding general anesthesia for surgery. Patient non eligible for monopolar RFA were either patients with HCC tumor size $>30 \mathrm{~mm}$ diameter, or patients with $<30 \mathrm{~mm}$ diameter HCC with localization prohibiting percutaneous RFA (not visible at US examination, localized in the upper the part of the liver, in segment I, exophytic/subapsular, etc).

We chose to assess efficacy of TACE + 3D-HDCRT in uninodular HCCs ineligible for potential curative options. 3D-HDCRT is particularly relevant for HCCs which topography allows radiation beams at focalizing onto a small part of the liver and sparing the surrounding non-tumorous area. ${ }^{23,24}$ In this way, it clearly appears that uninodular HCCs are the best candidates. In contrast, multifocal HCCs scattered in both hepatic lobes do not seem suitable due to the potential huge volume of irradiated non-tumorous liver parenchyma, thus prohibiting delivering high dose of radiation by risk of iatrogenic hepatitis. Herein, one single course of TACE was performed followed 10 days later by 3D-HDCRT to take 
advantage of the potential synergy between ionizing radiations and the cytotoxic chemotherapeutic agent (doxorubicin) inside the tumor. TACE induces hypoxic necrosis, followed by VEGF peak and regrowth of residual cancerous foci, this event happening early post-TACE. ${ }^{25}$ Thus it seemed important to deliver radiation therapy before re-growth of the residual cancer cells. To this aim, we used high dosage of photon therapy (54 Gy, 3 Gy per fraction, equivalent to 65-70 Gy total dose with 2 Gy per fraction) as compared to those previously published: 69 Gy with $1.8 \mathrm{~Gy}$ per fraction, or 62 Gy with 2 Gy per fraction. ${ }^{11,26-28}$

TABLE 5: Factors influencing TTR.

\begin{tabular}{|c|c|c|c|c|}
\hline $\begin{array}{l}\text { Cox Proportional-Hazards } \\
\text { Regression for Univariate and } \\
\text { Multivariate Analysis }\end{array}$ & $\begin{array}{c}\text { Univariate } \\
\text { analysis } \\
\text { HR }(95 \% \mathrm{CI})\end{array}$ & $\mathrm{P}$-value & $\begin{array}{c}\text { Multivariate analy- } \\
\text { sis } \\
\text { HR }(95 \% \mathrm{CI})\end{array}$ & $\begin{array}{l}\text { Wald test, } \\
\text { P-value }\end{array}$ \\
\hline Age older than 70 years & 0.75 & .55 & & \\
\hline Male gender & $\begin{array}{c}(0.30-1.90) \\
1.37 \\
(0.44-4.29)\end{array}$ & .58 & & \\
\hline Cirrhosis & $\begin{array}{l}1.48 \\
(0.48-4.56)\end{array}$ & .48 & & \\
\hline HBV etiology & $(0.02-1.39)$ & 10 & & \\
\hline HCV eti & 0.57 & .33 & & \\
\hline Alcohol etiology & $(0.63-3.86)$ & .33 & & \\
\hline Other etiology & $(0.94-6.80)$ & .06 & & \\
\hline Platelet count $<150.000 / \mathrm{mL}$ & $\begin{array}{c}1.46 \\
(0.60-3.56)\end{array}$ & 40 & & \\
\hline Albuminemia $<35 \mathrm{~g} / \mathrm{L}$ & $\begin{array}{c}1.07 \\
(0.30-3.78)\end{array}$ & $.90^{-}$ & & \\
\hline Bilirubinemia $>20 \mu \mathrm{M} / \mathrm{L}$ & $(0.65-5.08)$ & .25 & & \\
\hline $\mathrm{AFP} \geq 200 \mathrm{ng} / \mathrm{mL}$ & $\begin{array}{c}5.84 \\
(1.85-18.4)\end{array}$ & .002 & $\begin{array}{c}5.84 \\
(1.85-18.4)\end{array}$ & .002 \\
\hline BCLC stage non-A & $\begin{array}{c}0.38 \\
(0.08-1.64)\end{array}$ & .19 & "-ー - - - - & \\
\hline Tumor size $>50 \mathrm{~mm}$ & $(0.81-5.06)$ & .13 & & \\
\hline $\begin{array}{l}\text { Absence of complete response } \\
\text { after TACE + 3D-HDCRT }\end{array}$ & $\begin{array}{c}1.88 \\
(0.60-5.81) \\
\end{array}$ & .27 & & \\
\hline
\end{tabular}

TABLE 6: Adverse events within 12 months post TACE + 3D-HDCRT.

\begin{tabular}{lcccc}
\hline \hline Number of adverse events & Grade 1 & Grade 2 & Grade 3 & Grade 4 \\
\cline { 1 - 3 } & 3 & 1 & 3 & 0 \\
Digestive bleeding & 0 & 0 & 1 & 1 \\
Hepatic encephalopathy & 0 & 0 & 0 & 0 \\
Hepatic pain & 0 & 0 & 0 & 0 \\
Post-radiation pneumopathy & 1 & 1 & 0 & 0 \\
Albuminemia & 7 & 4 & 0 & 0 \\
SGOT/SGPT & 2 & 2 & 0 & 0 \\
Bilirubinemia & 2 & 4 & 0 & 0 \\
Alkaline phosphatase & 3 & 6 & 0 & 0 \\
Platelet count & 3 & 2 & 0 & 0 \\
Prothrombin time & 3 & 0 & 0 & 0 \\
Creatininemia & 4 & 2 & 0 & 0 \\
\hline \hline
\end{tabular}


We showed that TACE + 3D-HDCRT combination therapy is highly efficient for tumor destruction. Tumor size $\leq 50 \mathrm{~mm}$ greatly predicted CR (95\%) vs. $60 \%$ for HCCs $>50 \mathrm{~mm}$, with uncommon relapse (11\%) within radiation fields for CR pts. We previously reported that 3D-HDCRT monotherapy could lead to $80 \%$ CR for HCCs $\leq 50 \mathrm{~mm}$, but local recurrence rates were higher $(20 \%)$ than in the present TACE + 3D-HDCRT combination (11\%). ${ }^{18}$ Regarding this subset of HCCs $\leq 50 \mathrm{~mm}$, we further showed that TACE + 3D-HDRT leads to one and 3 -year overall survival rates of $80 \%$ and $54 \%$ (median, 39.6 months), quite similar to those reported in literature with percutaneous destructions or surgical resections. ${ }^{29}$ Surgical resection was reported as treatment of choice for HCCs $\leq 50$ $\mathrm{mm}$, whereas OLT or RFA, these latter being more prone for smaller HCCs $(\leqslant 30 \mathrm{~mm})$, could be alternative options in curative intent to treat. In cohorts of subset of HCCs $\leq 30 \mathrm{~mm}$, surgery is quite equivalent to RFA as illustrated by some studies where the one and 3-year survival rates were reported at $89 \%$ and $57 \%$ in surgical groups, and $91 \%$ and $71 \%$ in RFA groups $(\mathrm{P}=.30)$. However in the same study, surgery was more efficient than RFA for the subset of HCCs ranging from 31 to $50 \mathrm{~mm}$ : one and 3-year survival rates were reported at $92 \%$ and $68 \%$ in the surgical group vs. $81 \%$ and $42 \%$ in the RFA group $(\mathrm{P}=.03) \cdot{ }^{30-36}$ Unfortunately, significant number of patients with uninodular small size HCC cannot be treated by these potential curative options due to patient characteristics or tumour topography. Furthermore only a limited number of those patients can benefit of liver transplantation. They are thus intended to TACE that is a palliative option, giving less than $20 \%$ complete responses, and 20 months overall survival. ${ }^{5}$ Regarding HCCs $>50 \mathrm{~mm}$ in the present study, TACE + 3D-HDCRT led to $64 \%$ CR, $79 \%$ and $42 \%$ overall survival rates at one and 3-years (median, 30 months). Some published series reported that surgical resection of HCCs $>50 \mathrm{~mm}$ gives $69 \%$ and $37 \%$ overall survival rates at respectively 1 and 3-years (median, 20 months) 37,38 , thus at least comparable, although with a trends to inferiority, to our TACE + 3D-HDCRT data.

In previously published studies, predictive factors of prolonged survival post-TACE + 3D-HDCRT were liver functions as assessed by the Child-Pugh score, tumor size $(<50$ $\mathrm{mm} v s .50-100 \mathrm{~mm} v s .>100 \mathrm{~mm}$ ), absence of neoplastic portal vein invasion, total dose irradiation delivered to the tumor (60 Gy vs. $56 \mathrm{~Gy}$ vs. $48 \mathrm{~Gy}$ with $1.8 \mathrm{~Gy} /$ fraction). ${ }^{39} \mathrm{In}$ the present study, almost all patients were Child-Pugh A, devoid of portal vein invasion and the irradiation dose was constant (54 Gy, $3 \mathrm{~Gy} /$ fraction). We found pre-therapeutic AFP $<200 \mathrm{ng} / \mathrm{mL}$ as predictive factor of prolonged survival, and at a lesser extent since nonsignificant, tumor size $(\leq 50$ $\mathrm{mm}$ ) and CR. Furthermore, pre-therapeutic AFP $\geq 200 \mathrm{ng} / \mathrm{mL}$ and tumor size $>50 \mathrm{~mm}$ clearly appeared as predictive of tumor recurrence such as intra-hepatic metastasis since occurring mainly outside the radiation fields. Thus it's highly possible that pre-therapeutic AFP and tumor size predict the presence of micro metastasis spared in the liver parenchyma before TACE + 3D-HDCRT procedure. Although tumor response is likely a key factor for prolonged survival, this parameter did not appear as determinant in the present study since: i) most of patients were $C R$ and only a few were PR or $\mathrm{SD}$, thus prohibiting robust statistical comparisons; ii) all PR pts could subsequently benefit from additional RFA or TACE to obtain complete response on the residual living tumor tissue within the previously irradiated nodule.

Comparing our data with those previously published in the literature, the first study combining 3D-HDCRT (total 44-69.3 Gy, daily $1.8 \mathrm{~Gy} /$ fraction) and TACE was published in 1999 and enrolled patients with unresectable large size HCCs (mean $9 \pm 3.4 \mathrm{~cm}$ ). The objective response rate was $63.3 \%$, and survival reached $67 \%$ and $22.2 \%$ at one and 3-years, with 17 months overall survival. ${ }^{11}$ Although achieved in uncontrolled settings, subsequent studies compared TACE+3D-HDCRT to TACE monotherapy, and clearly isolated irradiation as an independent positive predictor of survival. The combination therapy gave higher response rates than TACE monotherapy $(47.4 \%$ vs. $28.1 \%, \mathrm{P}<.05)$, and additionally prolonged survival $(19$ vs. 10 months, $\mathrm{P}=$ $.0001) \cdot{ }^{13}$ Further studies evaluated increasing doses of radiation therapy on HCC in chemo-radiation strategies (up to 60 Gy in $7.5 \mathrm{~Gy} /$ fraction, equivalent to $87.5 \mathrm{~Gy}$ in $2 \mathrm{~Gy} /$ fraction) delivered by conformational hypofractionation. This radiation schedule led to higher response rates $(90.5 \%)$ and better overall survival reaching 25 months. ${ }^{39}$ Regarding safety, our data are rather encouraging since showing only $11.4 \%$ grade 3-4 toxicities, whereas previously published studies reported huge variability in values: $13-50 \%$ grade- 3 toxicities. ${ }^{40}$ The limited high grade toxicity observed in our study may be explained by the strict selection of patients at inclusion (Child-Pugh A) with uninodular HCC (limiting widespread irradiation of the liver parenchyma) and adjacent organs such as stomach for instance.

In parallel of 3D-HDCRT, other approaches such as stereotactic body radiotherapy (SBRT) reported exciting data for inoperable HCCs. SBRT allows the delivery of higher doses of radiotherapy as compared to 3D-HDCRT, with more accuracy to target the tumor volume and to spare the nontumorous surrounding liver parenchyma. In Jang's et al report ${ }^{41}$, a 3 fraction 51 Gy SBRT (range, 33-60 Gy) led to 87\% local control in a dose efficient manner for tumors ranging from 10 to $70 \mathrm{~mm}$, mean $31 \mathrm{~mm}$, median $30 \mathrm{~mm}$ (100\% in our study, with tumors ranging from 23 to $88 \mathrm{~mm}$, mean $49 \mathrm{~mm}$, median $50 \mathrm{~mm}$ ). The one, two and three year overall survival rates reached $82 \%, 63 \%$ and $55 \%$ respectively, median around 42 months with SBRT vs. $79 \%, 59 \%$ and $44 \%$, median 39.6 months in our TACE+3D-HDCRT study. Grade 3/4 toxicities were quite similar between Jang's reports and the present study (10\% vs. $11.4 \%)$. Prospective randomized controlled trials could compare each approach between SBRT and 
TACE+3D-HDCRT. Further the same team ${ }^{42}$, demonstrated that Child-Pugh A cirrhotic patients are more prone than B to undergo SBRT since giving more > grade-2 toxicities $(11.9 \%$ for Child-Pugh A vs. 36\% for B). In our study, 91\% of patients were Child-Pugh A, thus prohibiting to highlight any differential toxicity probability between Child-Pugh A and B patients.

\section{Conclusion}

Finally in the present study, it seems of interest to be aware that patients with HCC of poor prognosis due to ineligibility to surgical resection or RFA, might keep potential comparable efficiency for tumor control and survival probability thanks to TACE+3D-HDCRT combination therapy. However, randomized controlled studies are needed to definitely clarify this concern. Currently, the TACERTE study is under investigation. This is a multicentre, prospective, randomized, controlled phase 2B trial comparing TACE+3D-HDCRT vs. TACE alone for HCCs $<10 \mathrm{~cm}$ and ineligible to curative options.

\section{Conflict of interest}

The authors declare that they have no conflicts of interest. The authors alone are responsible for the content and writing of the paper.

\section{References}

1. El-Serag HB, Mason AC. Rising incidence of hepatocellular carcinoma in the United States. $N$ Engl J Med 1999; 340:745-50.

2. Parkin DM, Bray F, Ferlay J, Pisani P. Global cancer statistics 2002. CA Cancer J Clin 2005; 55:74-108.

3. Bruix J, Sherman M. Management of hepatocellular carcinoma: an update. Hepatology 2011; 53:1020-2.

4. Lo CM, Ngan H, Tso WK, et al. Randomized controlled trial of transarterial lipiodol chemoembolisation for unresectable hepatocellular carcinoma. Hepatology 2002; 35:1164-71.

5. Llovet JM, Real MI, Montana X, et al. Arterial embolisation or chemoembolisation versus symptomatic treatment in patients with unresectable hepatocellular carcinoma: a randomised controlled trial. Lancet 2002; 359:1734-9.

6. Bruix J, Sala M, Llovet JM. Chemoembolization for hepatocellular carcinoma. Gastroenterology 2004; 127:S179-88.

7. Bruix J, Sherman M; Practice Guidelines Committee, American Association for the Study of Liver Diseases. Management of hepatocellular carcinoma. Hepatology 2005; 42:1208-36.
8. Llovet JM, Burroughs A, Bruix J. Hepatocellular carcinoma. Lancet 2003; 362:1907-17.

9. Llovet JM, Bruix J. Systematic review of randomized trials for unresectable hepatocellular carcinoma: chemoembolization improves survival. Hepatology 2003; 37:429-42.

10. Llovet JM, Schwartz M, Mazzaferro V. Resection and liver transplantation for hepatocellular carcinoma. Semin Liver Dis 2005; 25:181-200.

11. Seong J, Keum KC, Han KH, et al. Combined transcathter arterial chemoembolization and local radiotherapy of unresectable hepatocellular carcinoma. Int J Radiat Oncol Biol Phys 1999; 43:393-7.

12. Guo WJ, Yu EX. Evaluation of combined therapy with chemoembolization and irradiation for large hepatocellular carcinoma. B J Radiol 2000; 73:1091-7.

13. Guo WJ, Yu EX, Liu LM, et al. Comparison between chemoembolization combined with radiotherapy and chemoembolization alone for large hepatocellular carcinoma. World J Gastroenterol 2003; 9:1697-701.

14. Shim SJ, Seong J, Han KH, et al. Local radiotherapy as a complement to incomplete transcatheter arterial chemoembolization in locally advanced hepatocellular carcinoma. Liver Int 2005; 25:1189-96.

15. Llovet JM, Di Bisceglie AM, Bruix J, et al. Design and endpoints of clinical trials in hepatocellular carcinoma. J Natl Cancer Inst 2008; 100:698-711.

16. Ten Haken RK, Lawrence TS, McShan DL, et al. Technical considerations in the use of 3-D beam arrangements in the abdomen. Radiother Oncol 1991; 22:19-28.

17. Dawson LA, Brock KK, Kazanjian S, et al. The reproducibility of organ position using active breathing control $(\mathrm{ABC})$ during liver radiotherapy. Int J Radiat Oncol Biol Phys 2001; 51:1410-21.

18. Mornex F, Girard N, Beziat C, et al. Feasibility and efficacy of high-dose three-dimensional-conformal radiotherapy in cirrhotic patients with small-size hepatocellular carcinoma noneligible for curative therapies - Mature results of the French phase 2 RTF-1 trial. Int J Radiat Oncol Biol Phys 2006; 66:1152-8.

19. Lawrence TS, Tesser RJ, ten Haken RK. An application of dose volume histograms to the treatment of intrahepatic malignancies with radiation therapy. Int J Radiat Oncol Biol Phys 1990; 19:1041-7.

20. Lawrence TS, Ten Haken RK, Kessler ML, et al. The use of 3-D dose volume analysis to predict radiation hepatitis. Int J Radiat Oncol Biol Phys 1992; 23:781-8.

21. McGinn CJ, Ten Haken RK, Ensminger WD, et al. Treatment of intrahepatic cancers with radiation doses based on a normal tissue complication probability model. JClin Oncol 1998; 16:2246-52. 
22. Late Effects of Normal Tissues (LENT) Consensus Conference. LENT SOMA scales for all anatomic sites. Int $J$ Radiat Oncol Biol Phys 1995; 31:1049-91.

23. Merle P, Mornex F, Trepo C. Innovative therapy for hepatocellular carcinoma: three-dimensional high-dose photon radiotherapy. Cancer Lett 2009; 286:129-33.

24. Dawson LA. Where does radiation therapy fit in the spectrum of liver cancer local-regional therapies? Semin Radiat Oncol 2011; 21:241-6.

25. Xiong ZP, Yang SR, Liang ZY, et al Association between vascular endothelial growth factor and metastasis after transcatheter arterial chemoembolization in patients with hepatocellular carcinoma. Hepatobiliary Pancreat Dis Int 2004; 3:386-90.

26. Cheng JC, Chuang VP, Cheng SH, et al. Local radiotherapy with or without transcatheter arterial chemoembolization for patients with unresectable hepatocellular carcinoma. Int I Radiat Oncol Biol 2000; 47:435-42.

27. Chia-Hsien Cheng J, Chuang VP, Cheng SH, et al. Unresectable hepatocellular carcinoma treated with radiotherapy and/or chemoembolization. Int $J$ Cancer 2001; 96:243-52.

28. Seong J, Park HC, Han KH, et al. Clinical results of 3-dimensional conformal radiotherapy combined with transarterial chemoembolization for hepatocellular carcinoma in the cirrhotic patients. Hepatology Research 2003; 27:30-5.

29. Khan MR, Poon RTP, Ng KK, et al. Comparison of percutaneous and surgical approaches for radiofrequency ablation of small and medium hepatocellular carcinoma. Arch Surg 2007; 142:1136-43.

30. Nagasue N, Kohno H, Chang YC, et al. Liver resection for hepatocellular carcinoma. Results of 229 consecutive patients during 11 years. Ann Surg 1993; 217:375-84.

31. Kotoh K, Sakai H, Sakamoto S, et al. The effect of percutaneous ethanol injection therapy on small solitary hepatocellular carcinoma is comparable to that of hepatectomy. Am J Gastroenterol 1994; 89:194-8.
32. Mazzaferro V, Regalia E, Doci R, et al. Liver transplantation for the treatment of small hepatocellular carcinomas in patients with cirrhosis. $N$ Engl J Med 1996; 334:693-9.

33. Izumi R, Shimizu K, Iyobe $\mathrm{T}$, et al. Postoperative adjuvant hepatic arterial infusion of lipiodol containing anticancer drugs in patients with hepatocellular carcinoma. Hepatology 1994; 20:295-301.

34. Fong Y, Sun RL, Jarnagin W, Blumgart LH. An analysis of 412 cases of hepatocellular carcinoma at a Western center. Ann Surg 1999; 229:790-9.

35. Curley SA, Izzo F, Ellis LM, et al. Radiofrequency ablation of hepatocellular cancer in 110 patients with cirrhosis. Ann Surg 2000; 232:381-91.

36. Decadt B, Sirlwardena AK. Radiofrequency ablation of liver tumors: Systematic review. Lancet Oncol 2004; 5:550-60.

37. Delis SG, Bakoyiannis A, Tassopoulos N, et al. Hepatic resection for hepatocellular carcinoma exceeding Milan criteria. Surg Oncol 2010; 19:200-7.

38. Schiffman SC, Woodall CE, Kooby DA, et al. Factors associated with recurrence and survival following hepatectomy for large hepatocellular carcinoma: a multicenter analysis. J Surg Oncol 2010; 101:105-10.

39. Wu DH, Liu L, Chen LH. Therapeutic effects and prognostic factors in three-dimensional conformal radiotherapy combined with transcatheter arterial chemoembolization for hepatocellular carcinoma. World J Gastroenterol 2004; 10:2184-9.

40. Hawkins MA, Dawson LA. Radiation therapy for hepatocellular carcinoma: from palliation to cure. Cancer 2006; 106:1653-63.

41. Jang WI, Kim MS, Bae SH, et al. High-dose stereotactic body radiotherapy correlates increased local control and overall survival in patients with inoperable hepatocellular carcinoma. Radiat Oncol 2013; 8:250-61.

42. Jung J, Yoon SM, Kim SY, et al. Radiation-induced liver disease after stereotactic body radiotherapy for small hepatocellular carcinoma: clinical and dose-volumetric parameters. Radiat Oncol 2013; 8:249-55. 